ISSN $2358-2$

\title{
Violência e saúde: múltiplas manifestações, respostas complexas
}

\author{
Violence: multiple manifestations, complex answers
}

\author{
Ana Carolina Soares Bertho ${ }^{1}$ (it) \\ 'Escola Nacional de Ciências Estatísticas (ENCE), Instituto Brasileiro de Geografia e Estatística (IBGE) - Rio de Janeiro (RJ), Brasil.
}

Como citar: Bertho ACS. Violência e saúde: múltiplas manifestações, respostas complexas. Cad Saúde Colet, 2021;29(esp.):211-215. https://doi.org/10.1590/1414-462X202199010300

A obra "Novas e velhas faces da violência no século XXI: visão da literatura brasileira no campo da saúde", organizada por Maria Cecília de Souza Minayo e Simone Gonçalves de Assis retrata as múltiplas faces da violência no Brasil por meio da produção científica no campo da saúde no início do século XXI. Constituído por 26 capítulos, o livro é resultado do esforço de 48 autores que selecionaram 2.477 textos publicados entre 2001 e 2013 e os analisaram criticamente. Trata-se da continuação de duas revisões anteriores, publicadas em 1990 e 2003, também elaboradas por pesquisadores do Claves (ENSP/ Fiocruz).

À primeira vista, as quatro partes que compõem a obra parecem se sobrepor, mas na realidade se complementam. A parte lé chamada "Violências e acidentes: bases referenciais do campo da saúde" e tem sete capítulos. Já a parte II, "Violências segundo ciclos de vida e gênero", é composta por quatro capítulos. Na parte III, "Violência nas instituições", há cinco capítulos. E, finalmente, na parte IV, "Violências em situações de vulnerabilidade", há 10 capítulos.

No primeiro capítulo, "Os múltiplos tentáculos da violência que afeta a saúde", as organizadoras afirmam que a violência é algo inerente à vida humana e às interações sociais. Destacam, no Brasil, o papel do tráfico de drogas e dos grupos de extermínio, a falta de investigação e de ações preventivas, a violência policial e a impunidade, levando ao aumento dos homicídios com o uso de armas de fogo, especialmente entre os jovens. Entre as vítimas, a maioria é negra, pobre e moradora de periferias urbanas.

O segundo capítulo explicita a metodologia e as bases de dados selecionadas. Incluíram-se apenas documentos da área de saúde. Os autores destacam o aumento da produção científica sobre a violência, passando de 19 textos até 1969 para 543 em 1990-2000 e 2.447 entre 2001 e 2013. Trata-se de um capítulo valioso, não só como parte essencial da obra, mas também como exemplo de rigor na elaboração de uma metodologia de pesquisa.

O capítulo 3 aborda os homicídios e as agressões. Os autores afirmam que os homicídios constituem a primeira causa de morte entre os homens de 15 a 44 anos no Brasil. Dos textos analisados, $97 \%$ tratam da violência física. Entre as lacunas identificadas nas pesquisas estão: a caracterização da juventude, o aprofundamento da variável de raça/cor e a violência contra LGTB, gestantes e mulheres vítimas de violência sexual.

As lesões e mortes no trânsito são o mote do capítulo 4. Somente em 2013, mais de 42 mil pessoas morreram em decorrência dessa causa. Ainda que os motociclistas jovens sejam as principais vítimas, em $87,6 \%$ dos textos estudados não há especificação da condição da vítima

Este é um artigo publicado em acesso aberto (Open Access) sob a licença Creative Commons Attribution, que permite uso, distribuição e reprodução em qualquer meio, sem restrições desde que o trabalho original seja corretamente citado.

\footnotetext{
Trabalho realizado na Escola Nacional de Ciências Estatísticas (ENCE) - Rio de Janeiro (RJ), Brasil.

Correspondência: Ana Carolina Soares Bertho. E-mail: carolina.bertho@ibge.gov.br

Fonte de financiamento: Conselho Nacional de Desenvolvimento Científico e Tecnológico (CNPq), Bolsa PQ-2.

Conflito de interesses: nada a declarar.

Recebido em: Jul. 12, 2019. Aprovado em: Ago. 15, 2019

Resenha: MINAYO, M.C.S.; ASSIS, S.G.A. (Org.) Novas e velhas faces da violência no século XXI: visão da literatura brasileira
} do campo da saúde. Rio de Janeiro: Fiocruz, 2017. 
no acidente. Tal lacuna prejudica e inviabiliza a adoção de medidas de proteção voltadas para os grupos mais vulneráveis.

O capítulo 5 apresenta outras causas externas de lesões e óbitos acidentais, incluindo quedas, queimaduras, intoxicações, afogamentos etc. Somente as quedas são responsáveis por $58,9 \%$ das hospitalizações. Os autores destacam a escassez de trabalhos sobre esse grupo de agravos, sendo que diversos eventos classificados nesse grupo são sequer citados.

A violência no trabalho é o tema do capítulo 6, a qual inclui as agressões físicas e verbais e os assédios moral e sexual, bem como os acidentes de trabalho. Alguns dos estudos selecionados destacam as consequências do assédio no trabalho, incluindo baixa autoestima, maior sensibilidade aos agravos à saúde física e mental, ansiedade, depressão, entre outros. Ressalta-se a escassez de textos sobre o tema, exceto entre os profissionais de saúde.

No capítulo 7, os autores tratam do tema da violência autoinfligida, ideações, tentativas de suicídio e suicídio consumado. Ainda que o país registre taxas relativamente baixas, observou-se um aumento de $29,5 \%$ nos últimos 25 anos. Os fatores de risco mais presentes são depressão, alcoolismo, uso de outras substâncias tóxicas, esquizofrenia, bipolaridade e histórias de violência física e sexual na família, entre outros. Enforcamento, intoxicações e envenenamento são os meios mais usados, mas há um aumento recente de mortes com o uso de armas de fogo ou de pessoas que se atiram de lugares altos. As autoras refletem que é necessário aprofundar a compreensão desse fenômeno por faixa etária e gênero.

O capítulo 8 aborda a violência contra crianças e adolescentes. As autoras destacam a importância das agressões por armas de fogo, sendo os adolescentes do sexo masculino os mais afetados. A temática da violência contra crianças e adolescentes aparece também no capítulo 12, que trata da violência intrafamiliar, e no capítulo 13, que tem como foco a violência na escola, sendo que, nesse último, há destaque para as investigações sobre o bullying, que só recentemente passou a ser identificado e estudado. Independentemente do local onde ocorra a violência, se no domicílio ou na escola, há fatores comuns associados, como exposição ao álcool e às drogas, abuso sexual, prostituição, problemas mentais, violência armada e trabalho infantil, que é visto como uma das maiores expressões da violência estrutural.

O capítulo 9 trata de "Homens e violências: relações naturalizadas e desafiadoras para a saúde". Os autores afirmam que a agressividade do homem seria vista como algo natural, muitas vezes usada para justificar a violência de gênero. Porém, trata-se de uma construção social. Vitimização e agressão seriam faces da mesma moeda. Em análises multivariadas, observouse que o risco de morte por homicídio é maior para os homens, podendo ser potencializado quando diz respeito a jovens, negros e pobres. Para os autores, para enfrentar a violência entre os homens, é preciso envolver outros setores da sociedade, além da saúde, e considerar as relações de forma mais ampla, incorporando a perspectiva de gênero.

O capítulo 10 aborda a violência contra as mulheres. Trata-se de um fenômeno frequentemente observado no âmbito familiar, sendo atravessado por marcadores sociais, sobretudo raça, etnia e classe social.

Apesar da ampliação em número e diversidade de estudos sobre a violência contra as mulheres, os autores apontam alguns subtemas a serem explorados, como a violência na gravidez e obstétrica no pré-natal e no nascimento, a promoção de comportamentos protetores, a resiliência e prevenção da violência e os trabalhos sobre a violência contra lésbicas, transexuais e travestis.

As formas visíveis e invisíveis de violência contra a pessoa idosa são tema do capítulo 11. A maior parte dos estudos dá ênfase às quedas, muito comuns entre as pessoas com mais de 60 anos e que respondem por $29 \%$ dos óbitos de idosos por causas externas. Entretanto, há uma lacuna de publicações sobre homicídios e sobre acidentes de trânsito, que têm participação importante nesse grupo etário.

O capítulo 12 tem como tema a violência intrafamiliar. A maior parte dos textos se refere a crianças e adolescentes, seguida por mulheres, homens (como autores de atos de violência), idosos e jovens. O homem, em geral, é visto como "vilão", como perpetrador da violência. As autoras defendem a importância de se estudar a violência a partir de uma visão sistêmica, reconhecendo que o fenômeno é composto por múltiplos fatores, incluindo o contextual, 
o temporal, o pessoal e o processual e que ocorre na relação entre as pessoas, e não dentro delas (nível intrapsíquico). Somente a partir da compreensão da complexidade desses fatores é possível estabelecer ações de enfrentamento e cuidado.

O atendimento a pessoas em situação de violência pelo Sistema Único de Saúde é o mote do capítulo 14. Houve um avanço na atenção às pessoas que sofreram violência nas últimas décadas, com a expansão de serviços para o atendimento e a criação de normas técnicas. Porém, ainda há problemas como desigualdades regionais da oferta, capacitação descontínua e ineficiente dos profissionais, dificuldades de atuar em rede e desarticulação entre serviços de saúde. As autoras apontam para a necessidade de introduzir o impacto da violência sobre a saúde como tema de formação em todas as carreiras da área da saúde.

A interface entre violência nas mídias e saúde pública é o tema do capítulo 15. Os textos mostram que os efeitos da mídia no comportamento infantojuvenil dependem de características individuais e que, à medida que as crianças crescem, aumenta-se a compreensão sobre a violência, desencorajando comportamentos agressivos. O papel da mídia é preponderante, mas o poder que ela tem sobre os indivíduos não é absoluto. As pesquisas apontam que a alta exposição a conteúdos envolvendo homicídios ou suicídios seria prejudicial por levar à banalização. Por outro lado, a mídia pode contribuir indicando serviços de atenção a pessoas em situação de violência e estratégias de prevenção, além de participar na mudança de hábitos e na construção de uma cultura de igualdade.

O capítulo 16 trata das relações entre religião, saúde e violência. Nas últimas décadas, observou-se o crescimento das pesquisas que destacam o papel protetivo da religião, sendo menor o número de trabalhos que problematizam criticamente seus benefícios. A religião levaria a um controle do consumo abusivo de álcool ou outras drogas, contenção da delinquência juvenil e apoio ou rechaço taxativo a pessoas que praticam aborto. Entretanto, a proposta de terapia de reversão da sexualidade ("cura gay") e o tratamento religioso para coibir o uso abusivo e a dependência de drogas em comunidades terapêuticas religiosas seriam práticas que conspirariam contra os direitos humanos dos cidadãos, ferindo também a laicidade do Estado.

O capítulo 17 aborda a violência contra as pessoas com deficiência. Os textos selecionados incluem violência doméstica e intrafamiliar, negligência, abusos físicos, psicológicos, sexuais, delinquência, violência institucional, violência estrutural e violência simbólica. A produção brasileira sobre o tema ainda é incipiente. As autoras defendem que é necessário aprofundar o conhecimento sobre a relação entre pobreza e deficiência, além de investigar o acesso aos benefícios com cuidados e reabilitação. Ainda é preciso melhorar a qualidade da notificação das deficiências e dos abusos sofridos pelas pessoas com tais características.

A violência contra a população negra é o tema do capítulo 18. Desde o período da escravidão, a sociedade brasileira foi marcada pelas desigualdades sociais, raciais e étnicas, o que resultou em uma estrutura social hierárquica que dificulta a inclusão dos negros e os expõe a altos índices de violência. Acidentes de transporte e homicídios aparecem como as principais causas de morte entre homens negros. Também nos casos de violência contra a mulher, o alvo principal é a mulher negra. Os autores afirmam que as condições estruturais e sociais que tornam os negros mais vulneráveis, o racismo e os altos índices de violência ainda são pouco explorados nas pesquisas.

A associação entre uso de álcool e outras drogas e violência é o mote do capítulo 19. As autoras explicitam que a classificação das drogas como lícitas e ilícitas não é sempre a mesma e muda de acordo com os interesses políticos, sociais e econômicos. Enquanto o uso das drogas lícitas é tolerado e até mesmo incentivado em algumas situações, as drogas ilícitas são comercializadas clandestinamente, afetando comunidades pobres e fazendo com que a ilegalidade esteja permeada pela violência. Para as autoras, o uso de drogas ilícitas não deve ser tratado como questão de polícia, mas sim de saúde pública. Os adolescentes do sexo masculino têm destaque nas pesquisas, não só pelo uso abusivo de álcool e outras drogas, mas também em estudos que articulam violência urbana, criminalidade e tráfico. As autoras concluem que é necessário investir em ações intersetoriais. 
O capítulo 20 trata da relação entre violência e saúde mental. De início, debate de que a saúde mental é mais do que simplesmente a ausência de transtornos mentais. A violência física de pais contra crianças e adolescentes se destaca na literatura. Há uma mudança na produção sobre o assunto, que antes era muito focalizada na relação entre saúde mental e violência doméstica e hoje discute as enfermidades mentais resultantes da violência. A violência é abordada nas pesquisas ao mesmo tempo como preditora para transtornos mentais e como consequência vivida por pessoas que têm tais transtornos e se tornam vítimas.

O capítulo 21 trata das violências sexuais (VS). As pesquisas mostram que pais e padrastos aparecem como os principais perpetradores de VS contra meninas. Na adolescência, aumentase a proporção de perpetradores desconhecidos, e, na idade adulta, a maior parte é parceiro íntimo ou desconhecido. Entre as lacunas encontradas estão aspectos relacionados à educação de gênero e ao quadro de valores que tornam crianças, adolescentes e mulheres vulneráveis a VS; às relações familiares após a denúncia de VS; e às representações de masculinidade entre os perpetradores. As autoras destacam a importância da formação e capacitação dos profissionais que atendem as pessoas que sofreram VS, que tratam das lesões, mas não têm rotinas de suporte técnico e emocional para lidar com as vítimas.

A violência contra lésbicas, gays, bissexuais, transexuais e travestis é o tema do capítulo 22. Os autores revelam que esse tipo de violência, categorizada como homofobia, vem ganhando espaço nos estudos acadêmicos, apesar da carência de dados sobre o assunto em todo o mundo. Em estudos sobre o perfil das vítimas de violência, destacam-se as pessoas com baixa renda e baixa escolaridade como as mais vulneráveis. Ainda que haja avanços sociais e na produção acadêmica sobre o tema, atualmente a população LGBT enfrenta dificuldades no cenário político, dificuldades para tratar do tema em ambiente escolar e de implementação de campanhas a seu favor na mídia em razão das forças conservadoras, inclusive no Congresso Nacional.

O capítulo 23 trata dos adolescentes em conflito com a lei. Os estudos revelam que os jovens têm participação maior como vítimas do que como autores de crimes, e pessoas com idade entre 16 e 18 anos foram responsáveis por apenas $0,9 \%$ dos crimes no país. As condições socioeconômicas desfavoráveis, contexto social violento e descrença no futuro aparecem como aspectos que tornam os jovens mais vulneráveis a figurar entre perpetradores e vítimas. A violência é parte do cenário no atendimento socioeducativo e penitenciário dos jovens, e questiona-se a redução da maioridade penal como solução para a segurança pública. A família e as relações intrafamiliares figuram, simultaneamente, como fatores de risco para o comportamento delinquente e como esferas importantes para a recuperação e a ressocialização dos jovens.

As relações entre violência e saúde na população encarcerada são o tema do capítulo 24. Os presos são vítimas de lesões, traumas e adoecimento em proporções maiores que o restante da população e estariam sujeitos à negligência e à omissão de socorro - que também constituem formas de violência. Nessa população específica, o envolvimento em brigas, as ameaças de morte e as disputas entre facções são as expressões mais comuns de violência. As autoras apontam que há pouco debate sobre os problemas estruturais que precisam ser solucionados para viabilizar a adoção de medidas de promoção e qualidade de vida entre os detentos. Outra lacuna é a ausência de textos abordando a relação entre agentes prisionais e presos. Finalmente, as autoras defendem que o sistema judiciário deveria aparecer nos estudos e publicações, uma vez que mais de $40 \%$ dos presos no Brasil não têm sentença atribuída.

O capítulo 25 trata da violência contra a população de rua, que, em geral, é composta por trabalhadores que vivem na rua e não é homogênea. A produção científica mostra que, por um lado, a violência desencadeia a ida para a rua (um ponto em comum a essas pessoas é a trajetória marcada por diversas formas de violência), e, por outro, a população em situação de rua também é vítima de violência. Para os autores, ainda é preciso mapear questões como as estratégias de sobrevivência, os efeitos da violência sobre a saúde física e mental e a criação de referenciais para inclusão social e identificação dessa população.

O último capítulo investiga o aporte das neurociências para se estudar a violência, provocando uma reflexão sobre a integração entre biologia e meio social. Para isso, os autores 
exploram algumas definições. A primeira é a agressividade, que se refere a uma conduta própria dos animais e que existe mesmo antes do surgimento do homem. Tem componentes biológicos, mas se expressa de acordo com a genética, o temperamento e a neurofisiologia. Já a violência é algo exclusivamente humano e seria uma expressão de agressividade; ainda, ela não é um ato isolado e pode ser estudada individualmente ou em grupo. Os textos analisados mostram que, biologicamente falando, poderia existir uma tendência maior de a pessoa agir com violência e agressividade. Tal característica não deve ser ignorada, mas os autores ressaltam a importância de se considerar o contexto social e alertam para o risco de se estigmatizar a pessoa com perfil criminoso, que seria violenta em suas origens. O exemplo extremo dado é o de um deputado defensor da redução da maioridade penal e do aborto de bebês com tendências criminosas.

Alguns aspectos comuns são reportados em diversos capítulos. O primeiro, positivo, é o aumento no número de estudos abordando as múltiplas formas de violência, bem como a maior visibilidade dada a determinados temas, como violência contra pessoas LGBT e a população de rua. Entre as críticas feitas no livro, uma delas é que ainda são relativamente poucos os estudos com recortes por raça/cor da pele, bem como por classes sociais. Estratégias de prevenção, enfrentamento e resiliência diante da violência também são apontados como áreas que precisam ser mais exploradas na literatura. Outra lacuna diz respeito à escassez de investigações interseccionais sobre determinados temas, como violência contra a mulher. De acordo com as discussões apresentadas, fica claro que essa falha, muitas vezes, é apenas um reflexo da fragmentação das ações governamentais, que acabam por envolver apenas o setor de saúde, quando, na verdade, precisariam ter articulação com a abordagem social.

$\mathrm{O}$ acesso às armas de fogo aparece como fator diretamente relacionado à violência, especialmente entre crianças e adolescentes e nos casos de violência autoinfligida. Tal constatação é importante e deve ser considerada com toda a seriedade que o tema exige em um contexto no qual se tornou mais fácil o acesso às armas para cidadãos comuns.

\section{AGRADECIMENTOS}

A autora agradece o apoio recebido do Conselho Nacional de Desenvolvimento Científico e Tecnológico (CNPq). 